\title{
The Scholarship of Teaching and Learning: Transformation and Transgression
}

\author{
Laura Bolf-Beliveau, PhD \\ Associate Professor, Department of English \\ University of Central Oklahoma
}

Chapter Five of The Scholarship of Teaching and Learning Reconsidered (2011) suggests that traditional research scholarship methodology can inform and reform the ways in which we value and evaluate teaching. The authors discuss applying research methodology as way to complete this process. This article suggests that using theoretical frames, often used in qualitative methodology, creates another way to transform perceptions of the scholarship of teaching and learning. Two theoretical frames, transformative learning and critical consciousness, are explored and applied to the author's own teaching experiences and discipline mandates.

The authors of The Scholarship of Teaching and Learning Reconsidered offer a powerful statement in their fifth chapter: "Cultural change seldom moves easily or evenly through complex systems; it can take years of advocacy, activism, and experience to reach that Gladwellian tipping point" (Hutchings, Huber, \& Ciccone, 2011, p. 105). This is particularly true as they discuss ways in which the scholarship of teaching and learning (SoTL) can "work purposefully to bring faculty roles and rewards into alignment with a view of teaching as scholarly work" ( $p . x x)$. Hutchings, Huber, and Ciccone (2011) suggest we craft guidelines for "evaluation, documentation, and peer review that adequately recognize the scholarship of teaching and learning" ( $p . x x$ ).

There is little dissension on my part. As a teacher educator with over twenty years in the field of English education, I have engaged in teaching that closely relates to the scholarship as described by the authors that suggest this type of work "exhibits clear goals, adequate preparation, appropriate methods, significant results, effective presentation, and reflective critique" (Hutchings, Huber, $\&$ Ciccone, 2011, p. 91). Both teaching and research can use these categories to better understand student learning. Absent from that list, however, was an element of research that I find highly useful as a qualitative researcher: the theoretical frame. Theoretical frames use a particular theory, stance, or philosophy as a guide to the construction of research questions, completion of literature reviews, collection and analysis of data, and summary of findings. That theory also helps to make assumptions and form hypotheses for conclusions and implications. For example, previous research of mine (Bolf-Beliveau, 2007) studied first-year female middle and high school English teachers. The study focused on their emotional responses to difference or disrupting forces in their classrooms. To better understand these women's lived experiences, I read the data from the perspective of feminist poststructuralist theory. My conclusions, therefore, discuss subject position, language, and discourse. A theoretical frame can direct much of this type of research.

This article suggests that theoretical frames can also be useful when teacher-researchers use the philosophical underpinnings of SoTL. In fact, combining theoretical frameworks, such as transformative learning and transgression/critical consciousness, as done below, can help to develop more "elaborate" and "nuanced" (Hutchings, Huber, \& Ciccone, 2011, p. 104) understandings of the link between teaching and research. For the purposes of this article, the term "teacher-researcher" will denote college and university level academic positions that require both teaching and scholarship for promotion and tenure. However, this term will also be used to describe faculty who engage in the praxis of teacher as researcher and researcher as teacher. These individuals engage in the scholarship of teaching and the teaching of scholarship. The two 
theoretical frames discussed below will show how a philosophical stance can inform,/reform/deform the teacher-researcher. The first frame describes transformative learning, an integral part of my university's mission, as a powerful framework for understanding SoTL. The second focuses on transgression, as defined by bell hooks, as another method to investigate the possibilities and problems of SoTL.

Transformative learning can be used as a theoretical frame to see teaching as "scholarly work" (Hutchings, Huber, \& Ciccone, 2011, p. xx). My institution, the University of Central Oklahoma (UCO), has a Center for Excellence in Transformative Teaching and Learning (CETTL) that provides resources for faculty to implement these principles. In the document "What is Transformative Learning? (Pt. 1)," CETTL describes transformative learning from the student's perspective as a disorienting dilemma, an ongoing self-examination, a critical assessment of assumptions, an exploration of options, etc. Then a connection is made to what is valued at our institution:

At UCO, this is exactly what we aspire to accomplish in students' lives and in their learning. Through exposure to the Central Six tenets, we work to provide the learning environment that makes it more likely students will experience transformations in their thinking than if they went to college at a place which did not-at least consciously and explicitly-attempt to create such opportunities (CETTL, 2012, p. 1).

The Central Six tenets are Discipline Knowledge, Leadership, Problem Solving (Scholarly and Creative Activities), Service Learning/Civic Engagement, Global and Cultural Competencies, and Health and Wellness. In course syllabi, faculty must indicate how each course incorporates these transformative categories.

In another publication, CETTL explains that 'You can't 'make' a Transformative Learning experience happen inside students' head, but you can intentionally create the activities and environments within which it is far more likely to occur, then assess how frequently students report having such experiences" (2013, p. 1). Reflection is a "big part" of transformative learning, so using student journals, formative feedback, and student portfolios can help professors collect data and track students over time (CETTL, 2013, p. 2-3). Although the current mandated student evaluation process does not yet align with transformative learning and our Central Six, the university is providing faculty with a lens through which to view and think about our scholarship of teaching and learning. When applied to Exhibit 5.1 in Hutchings, Huber, and Ciccone's Chapter Five, we see that UCO's transformative learning theoretical frame and CETTL resources help faculty frame their scholarship of teaching and learning in the areas of Clear Goals, Adequate Preparation, Appropriate Methods, Significant Results, and Reflective Critique (p. 92). Any Effective Presentation would follow as faculty publish the results of their success with transformative learning within tenure and promotion documents and within or without traditional means like presentations, articles, and the like. The framework of transformative learning could provide a way in which teaching and learning is valued and evaluated.

When a university works toward establishing a theoretical framework of teaching and learning, teacher-researchers are provided the opportunity to better their teaching while managing institutional mandates. This is an obvious advantage; individuals are aligned with a philosophical stance that is privileged by the institution, and mirroring such a stance builds efficacy for the teacherresearcher. However, if a teacher-researcher is not in agreement with the university's mission and theoretical stance and does not use it, there are possible negative ramifications such as delays in promotion and tenure. My own work as a teacher-research uses the tenets of transformative learning as described above; however, I combine transformative learning with another theoretical frame, one that has cause contention within my classroom. This additional layer, I believe, is a 
powerful tool that accentuates transformative learning. Unfortunately, this theory is much more political in nature and suggests that great care be taken when teacherresearchers use a philosophy that will invite debate.

In Teaching to Transgress (1994), bell hooks states:

The academy is not paradise. But learning is a place where paradise can be created. The classroom with all its limitations remains a location of possibility. In that field of possibility we have the opportunity to labour for freedom, to demand of ourselves and our comrades, an openness of mind and heart that allows us to face reality even as we collectively imagine ways to move beyond boundaries, to transgress. This is education as the practice of freedom (p. 207).

Certainly hooks speaks to Chapter Five in The Scholarship of Teaching and Learning Reconsidered: valuing teaching and evaluating teaching have the potential for and offer the possibility of freedom for all classroom participants. Boundaries within classrooms shift in multiple ways, and blurring those boundaries offers the greatest potential of valuing and evaluating teaching. The classroom space should be one of transformation and transgression.

However, as Hutchings, Huber, and Ciccone (2011) suggest, "Classroom innovation is always risky" ( $p$. 88). As I describe below, my use of transgression paired with transformative learning was not an easy one. I teach a course entitled Young Adult Literature since 1980, an English department offering for undergraduates and graduate students. Although this course is open to any major, the majority of students are English education majors, and the course focuses on a plethora of young adult titles written for ages 10-18. Students read fourteen books during the semester and the course focuses on these essential questions:

1. How does young adult literature affect identity formation in adolescents?

2. In what ways does this genre inform one's critical literacy?

3. How do individual subject positions affect reading and understanding?

4. Does young adult literature provide opportunities for adolescents to better understand social justice?

My theoretical stance is grounded in UCO's tenets of transformative learning, but is also enhanced by Paulo Friere's critical consciousness, a method of transgression. This additional theoretical frame is clearly explored in the first two weeks of the course. Shor (1993) specifies four qualities of critical consciousness: power awareness, critical literacy, desocialization, and self-organization/self-education ( $p$. 32-33). I ask students to think about these concepts from their own perspective and that of the adolescents that read the book. While this stance does indeed meet the imperative of UCO's transformative learning and Central Six, I also push my students to transgress, to move beyond the boundaries of their own experience.

For the purposes of this article, I will focus on how two elements of critical consciousness provide a theoretical frame by which my scholarship of teaching and learning can be assessed. First, I ask students to think about how society and history informs human action, what Shor (1993) calls "knowing who exercises dominant power in society for what ends and how power is currently organized and used in society" ( $p .32$ ). I also focus on desocialization, "recognizing and challenging the myths, values, behaviors, and language learned in mass culture; critically examining the regressive values operating in society...which are internalized into consciousness" (Shor, 1993, p. 32). Both of these become contentious when we discuss David Levithan's Boy Meets Boy.

Published in 2003, Levithan's work is set in a utopian society where most people accept and celebrate Lesbian/Gay/Bisexual/Transgendered/Questioning (LGBTQ) individuals and communities. Paul, the protagonist of the story, was the first openly gay third-grade president and now as a high school sophomore, fits in 
with almost everyone at his school. The novel is a love story that mirrors many traditional tropes of young adult romance novels: a love triangle, a misunderstanding that leads to a break up, and the eventual happy ending. What is unique, of course, is that these tropes are applied to nonheterosexual relationships. In addition to reading the novel, students explore several academic articles that discuss the implications of LGBTQ young adult literature for all adolescent readers. We also read about gender performativity and Queer Theory.

One semester I also provided students with Chase and Ressler's (2009) "An LBGT/Queer Glossary." One entry proved quite upsetting to a student.

Homophobia: The irrational fear of LGBT people and those perceived to be LGBT, their sexual relationships, and their gender expressions (p. 24).

This student fixated on the word "irrational" and indicated that she thought homosexuality was morally wrong, but that did not make her irrational. I prompted her to think about the situation from the position of an LGBTQ student. She was not moved by that suggestion. I asked questions that suggested looking at the definition from the perspective of critical consciousness. How does the definition challenge our perceptions? How might it disrupt heteronormativity? The class then reminded me that we were in "the buckle of the Bible Belt." That proved to be enough explanation for the majority of the students who were ready to move to the next subject. Many of the students were not interested in interrogating power structures or challenging myths.

Ironically, the next novel had the same goals of interrogating power structures and challenging myths. The novel's subject, however was much more appealing to the students. The novel was Stork's (2011) Marcelo in the Real World, a story about an adolescent boy with an Asperger's-like syndrome. Marcelo's father demands that he work in a law firm one summer, and there Marcelo discovers how different the "real world" is. Marcelo grapples with issues of sexual attraction, bullying, injustice related to poverty, and prejudice. As with Boy Meets Boy, students are asked to read supplementary material to extend their understanding of the novel and critical consciousness. One piece, Miller's (2012) "Mythology of the Norm: Disrupting the Culture of Bullying in Schools" states:

The mythology of the "norm" has direct repercussions for schools, and its ideological reinforcement is the primary cause of bullying today. Though it is difficult to pinpoint an origin for "the norm," the medical model and its systemic structural power is one powerful institution that perpetuates this mythology (p. 107).

Like the definition of homophobia, Miller's piece was used to explore power relationships and accepted myths of our society. Unlike the definition of homophobia, students immediately engaged with Miller's statement and used it to evaluate the effectiveness of the book and its relationship to adolescent identity formation. Marcelo in the Real World was listed as a favorite of the semester, and students used it to discuss how the medical model and Disability Theory helped them see the injustices in Marcelo's world. They often selected the book as one that could help adolescents think about the importance of social justice.

Although this example is limited to one teacher-researcher's work with students studying literature, it could be applicable to those of us teaching science and discussing evolution theory. Or, teacher-researchers in the nursing field may face dissonance when discussing end-of-life choices. A theoretical stance, like one of critical consciousness, of transgression, can be, as Shor (1993) suggests, political. Classrooms can become "contact zones" (Pratt, 1991). Sometimes these contact zones produce transformation and transgression. Sometimes neither of these occurs. In either case, those of us who enjoy the praxis of teacher as researcher and researcher as teacher can find great joy in the interplay between 
transformation and transgression. While issues of LGBTQ caused dissonance in my literature course, the classroom was a vibrant space for learning. But the political nature of transgression means that the teacher-researcher must be willing to take risks to merge two theoretical frames as I did, and there could be negative implications for those interested in using political theoretical frameworks. While the advantages of using transformational learning by itself include a close alignment with institutional belief systems, the disadvantage of pairing transformative learning with transgression would be producing contact zones that may disengage students or complicate institutional demands like preparing promotion and tenure materials. If student evaluations show anger towards the stance being used by a teacherresearcher, then that data could be used as a way to punish the individual. Transgression as a means of transformation is not a given outcome of joining these two stances.

However, a strength of Hutchings, Huber, and Ciccone's discussion of SoTL is that it offers broad recommendations that "must be tailored and adapted to each campus's distinctive mission, history, and culture" (2011, p. xix). Each discipline and college or university setting must establish these based on a variety of imperatives. For example, my work with critical consciousness aligns with that mandated by accreditation standards. The National Council of Teachers of English (NCTE) and the National Council of Accreditation for Teacher Education (NCATE) require that I provide data for this standard:

\section{Professional Knowledge and Skills}

VI. Candidates demonstrate knowledge of how theories and research about social justice, diversity, equity, student identities, and schools as institutions can enhance students' opportunities to learn in English Language Arts.

Element 1: Candidates plan and implement English language arts and literacy instruction that promotes social justice and critical engagement with complex issues related to maintaining a diverse, inclusive, equitable society.

Element 2: Candidates use knowledge of theories and research to plan instruction responsive to students' local, national and international histories, individual identities (e.g., race, ethnicity, gender expression, age, appearance, ability, spiritual belief, sexual orientation, socioeconomic status, and community environment), and languages/dialects as they affect students' opportunities to learn in ELA (2012, p. 2).

Therefore, both my teaching and my students' learning must demonstrate knowledge and application of issues related to social justice. My use of critical consciousness in this young adult literature course helps achieve these goals. Other disciplines may have similar requirements for accreditation or governing entities that suggest best practices. The advantage of using my institution's commitment to transformative learning and my discipline's commitment to transgression through political theories like social justice is that learning is constructed within larger frameworks, and students can find their place among/between/within these systems.

The strength of SoTL, I believe, lies in its blurring of boundaries, its own transgressive potential. As hooks (1994) states, academic freedom should transgress boundaries. By applying traditional research methodology-including a theoretical frame-to teaching and learning, faculty and students have the opportunity to see academia from a much more holistic perspective. Hutchings, Huber, and Ciccone (2011) tell us that cultural change is complex and takes many years to achieve; however, their text lays the groundwork for such change, and I believe their arguments help scholars/ researchers/students raise their own critical consciousness of what academic communities can become. We may not be at the Gladwellian tipping point quite yet, but The Scholarship of Teaching and Learning Reconsidered shows it is within our reach. 


\section{References}

Bolf-Beliveau, L. (2007).

English/language arts teachers' emotional response to difference: $A$

feminist poststructural analysis. (Unpublished dissertation). University of Oklahoma, Norman, OK.

\section{Center for Excellence in}

Transformative Teaching and Learning (CETTL). (2012). "What is Transformative Learning? (Pt. 1)." Retrieved from:

http://www.uco.edu/academicaffairs/cettl/TLGuideFiles/2012-03tl.pdf

Center for Excellence in Transformative Teaching and Learning (CETTL). (2013). "Assessing Transformative Learning (Pt. 2): Doing and Measuring TL." Retrieved from:

http://www.uco.edu/academicaffairs/cettl/cettl-files/newsletterdocs/2013-02/2013-02-

newsletter. pdf\#Page $=1$

Chase, B., \& P. Ressler. (2009). “An LBGT/queer glossary." English Journal, 98(4), 23-24.

hooks, b. (1994). Teaching to transgress. Education as the practice of freedom. London: Routledge.
Hutchings, P., Huber, M.T., \& Ciccone, A. (2011). The scholarship of teaching and learning reconsidered. Stanford, CA: JosseyBass.

Levithan, D. (2003). Boy meets boy. New York, NY: Alfred A. Knopf.

Miller, S.J . (2012). "Mythology of the norm: Disrupting the culture of bullying in schools." English Journal, 101(6), 107-109.

National Council of Teachers of English (NCTE). (2012).

“NCTE/NCATE standards for initial preparation of teachers of secondary English language arts, grades 7-12." Retrieved from: http://www.ncte.org/library/ NCTEFile s/Groups/CEE/NCATE/ApprovedStand ards_111212.pdf

Pratt, M.L. (1991). "Arts of the contact zone." Profession, 33-40.

Shor, I. (1993). "Education is politics: Paulo Freire's critical pedagogy." In P. McLaren \& P. Leonard (Eds.), Paulo Freire: A critical encounter. (p. 25-35). London: Routledge.

Stork, F.X. (2011). Marcelo in the real world. New York, NY: Scholastic.

Laura Bolf-Beliveau is an associate professor in the Department of English at the University of Central Oklahoma, where she coordinates the English education program. A former high school teacher, Dr. Bolf-Beliveau's research interests include how teachers' dispositions toward difference affect their literature instruction and how preservice teachers' beliefs about social justice affect their pedagogy. She also studies how popular culture intersects with theory. Most notably, Dr. BolfBeliveau has written about HBO's The Wire and its depiction of critical consciousness. 